Article

\title{
Vibrometry Assessment of the External Thermal Composite Insulation Systems Influence on the Façade Airborne Sound Insulation ${ }^{+}$
}

\author{
Daniel Urbán ${ }^{1, *}$, N.B. Roozen ${ }^{2,3}{ }^{\circledR}$, Herbert Muellner ${ }^{4}$, Peter Zat'ko ${ }^{2}$, \\ Alexander Niemczanowski ${ }^{4}$, Monika Rychtáriková ${ }^{1,5}$ and Christ Glorieux ${ }^{3}$ \\ 1 STU Bratislava, Faculty of Civil Engineering, Radlinského 11, 81368 Bratislava, Slovakia; \\ monika.rychtarikova@stuba.sk \\ 2 A\&Z Acoustics s.r.o., Repašského 2, 84102 Bratislava, Slovakia; bert.roozen@kuleuven.be (N.B.R.); \\ akustika@akustika.sk (P.Z.) \\ 3 Laboratory of Acoustics, Soft matter and Biophysics, Department of Physics and Astronomy, KU Leuven, \\ Celestijnenlaan 200D, B-3001 Heverlee, Belgium; christ.glorieux@fys.kuleuven.be \\ 4 Versuchsanstalt TGM, Fachbereich Akustik und Bauphysik, Wexstrasse 19-23, 1200 Wien, Austria; \\ hmuellner@tgm.ac.at (H.M.); aniemczanowski@tgm.ac.at (A.N.) \\ 5 KU Leuven, Faculty of Architecture, Hoogstraat 51, 9000 Gent/Paleizenstraat 65, 1030 Brussel, Belgium; \\ monika.rychtarikova@kuleuven.be \\ * Correspondence: daniel.urban@stuba.sk; Tel.: +421-259-274-436 \\ $+\quad$ This paper is based on the authors' presentation: Measuring the sound insulation of external thermal \\ insulation composite system (ETICS) by means of vibrometry, which was orally presented at Forum \\ Acusticum 2017, Boston, MA, USA, 25-29 June 2017.
}

Received: 21 February 2018; Accepted: 30 March 2018; Published: 2 May 2018

Featured Application: The work presented in the paper, relates to building physics, specifically to building acoustics. Results can be applied in engineering practice and facades development research.

\begin{abstract}
This paper verifies the impact of the use of an external thermal composite system (ETICS) on air-borne sound insulation. For optimum accuracy over a wide frequency range, classical microphone based transmission measurements are combined with accelerometer based vibrometry measurements. Consistency is found between structural resonance frequencies and bending wave velocity dispersion curves determined by vibrometry on the one hand and spectral features of the sound reduction index, the ETICS mass-spring-mass resonance induced dip in the acoustic insulation spectrum, and the coincidence induced dip on the other hand. Scanning vibrometry proves to be an effective tool for structural assessment in the design phase of ETICS systems. The measured spectra are obtained with high resolution in wide frequency range, and yield sound insulation values are not affected by the room acoustic features of the laboratory transmission rooms. The complementarity between the microphone and accelerometer based results allows assessing the effect of ETICS on the sound insulation spectrum in an extended frequency range from $20 \mathrm{~Hz}$ to $10 \mathrm{kHz}$. The modified engineering $\Delta R$ prediction model for frequency range up to coincidence frequency of external plaster layer is recommended. Values for the sound reduction index obtained by a modified prediction method are consistent with the measured data.
\end{abstract}

Keywords: building acoustics; vibrometry assessment; facade airborne sound insulation; sound reduction index improvement; prediction model; external thermal composite system (ETICS) 


\section{Introduction}

The use of composite thermal insulation systems on external walls to improve the energy efficiency of buildings has been a common method in Middle European countries for many decades. External thermal insulation composite systems (ETICS), consisting of a thermal insulation layer placed on the external side of the wall cladding of a building, covered by a thin solid layer of plaster-like material, offer an adequate solution against thermal energy losses, while keeping the installation cost low and application procedure simple. Building physics research on ETICS involves not only thermal insulation performance [1], but also moisture infiltration in existing systems in newly developed materials in terms of bio-deterioration. [2-4] Extensive studies on optimization of ETICS design were published with respect to both thermal properties and moisture penetration $[1,5]$.

While wall insulation layers in the 1980s were typically $40-80 \mathrm{~mm}$ thick, the current criteria of EU energy policy and the predictions of EAE (European Association for External Thermal Insulation Composite Systems) require (depending on EU country) a thermal insulation layer with thickness between $200 \mathrm{~mm}$ and $300 \mathrm{~mm}$, in particular if passive house standards have to be met [6,7]. In the case of renovations and energy performance upgrades of existing buildings, by virtue of its non-invasive character, the use of ETICS is one of the most straightforward approaches to improve thermal insulation.

An important challenge for the implementation of ETICS is to improve the thermal insulation properties of exterior walls of buildings while preserving or ideally improving other essential building physics parameters and aspects of architectural aesthetics [8-11]. In the case of thermal insulation systems, in which a mineral wool layer is properly placed in the cavity between two massive layers, acoustic insulation performance also improves. This is thanks to sound absorptive properties of mineral wool that leads to damping of acoustic resonances in the cavity between the two massive layers. However, when a mineral wool layer is used in an ETICS configuration, sound insulation of an external wall might paradoxically decrease compared to situation in which only one bare walls are used [12,13]. Despite the added mass, the addition of a thin solid layer with a soft layer in between the outside air and a massive wall can have an acoustic impedance matching effect, increasing sound transmission from the air to the wall. Compared to the original acoustic insulation spectrum of the bare wall, the insulation spectrum after application of ETICS shows a dip around the mass-spring-mass $(\mathrm{m}-\mathrm{s}-\mathrm{m})$ resonance frequency of the two ETICS layers, due to the thin solid layer acting as a responding mass, and the thermal insulation layer as spring [9,13-19]. Typically, the resonance frequency lies in the part of the spectrum where human hearing is quite sensitive, such that, even for a small effect on the single number rating $R_{W}$ [20], the effect of ETICS on the sound insulation is likely to be audible.

In a recent revision of the Environmental Noise Directive (END) [21], it was stated that noise pollution continues to be a source of health effects [22] such as sleep disorders with awakenings [23], learning impairment [24], and hypertension ischemic heart disease [25]. The outer and inner walls of habitations represent, together with the windows, the first and most important defense for citizens from night noise, avoiding the above reported negative health effect. Thus, the use of composite thermal insulation systems also needs to be investigated from building acoustics point of view.

Several studies based on sound insulation measurements according to the ISO $10140[16,26,27]$, have reported effects of ETICS on parts of the insulation curve between $-8 \mathrm{~dB}$ and $+19 \mathrm{~dB}$. Even in cases where ETICS application results in a net increase of $R_{\mathrm{W}}$, the dip in the insulation curve, which occurs typically at rather low frequencies, can pose a considerable problem when insulation against traffic noise is concerned [28-31]. The sophisticated numerical prediction model to determine ETICS cladding system transmission loss was introduced based on transfer matrix method [32,33]. Discussions on harmonization and standardization of assessment procedures of the sound insulation in dwellings resulted in EU networking action [34]. The particular impact of noise from road, rail and air traffic is expressed in the spectrum adaptation terms $C$ and $C_{\text {tr }}$ [20]. In some countries, spectrum adaptation terms are not considered, but the contribution of low frequencies is included by means of extended assessment range, i.e., from 50 to $5000 \mathrm{~Hz}$ [35-39]. In [13,40], the insulation of low frequency noise 
produced by traffic is considered by calculation of single number quantities $R_{W}+C_{t r}$ or $R_{W}+C_{t r, 50-5000}$. In the case of ETICS, the adapted single number quantities rate the insulation performance substantially lower than $R_{\mathrm{W}}$, due to the dip in low frequencies. In some cases, the adapted single number quantity is lower after applying ETICS walls than before. This motivates the research on how to affect the ETICS dip by tuning the resonance frequency of the system into less audible lower frequencies [41] or by reducing the depth of the dip.

In current engineering design practice, the influence on the sound insulation due to a planned refurbishment of an outer wall $\Delta R_{W}$ (sound reduction index improvement) is often predicted by empirical relations. Based on extensive investigations by Weber et al. [13], a semi-empirical approach involving the spectrum adaptation terms $C$ and $C_{t r}$ has been implemented in the recent draft of ISO 12354-1 [42]. This has led to sound insulation values that are more adequate in relation to subjective perception.

The estimated $\Delta R_{W}$ due to the ETICS is then added to the weighted sound reduction index value $R_{W}$ (or $R_{W}+$ spectrum adaptation term) of the bare original wall to get the resulting sound reduction index of the entire assembly.

To assess the effects of ETICS on the perception of outdoor noise transmitted into building interior and thus its impact on the indoor acoustic comfort, assessment of the sound transmission properties is needed in the whole audible range, which is not always the case. In this paper, we report on laboratory sound insulation measurements using standardized sound pressure measurement techniques as well as vibrometry method [42]. Until now, no measurement techniques have been standardized or proposed that would allow for reliable quantification of sound transmission at low frequencies (i.e., lower than Schroeder frequency of receiving room, which is typically around $250 \mathrm{~Hz}$ ) [43]. Here, we exploit the advantages of vibrometry to assess the impact of the installation of ETICS on the airborne sound insulation down to $50 \mathrm{~Hz}$. The resonant behavior at low frequencies that goes along with the use of ETICS is accurately determined, unaffected by room acoustic aspects of the laboratory transmission rooms. In vibrometry, surface vibrations are mapped, resulting in operation deflection shapes (ODS). From the detailed information about vibrations, the sound power radiated by the measured element can be determined directly avoiding the influence of room resonances [44,45]. This approach is more reliable than conventional acoustic (i.e., microphone-based) methods, as, in the latter method, a diffuse acoustic field is assumed, which is not the case in the lower frequency range. Vibrometry also allows the determination of the radiation efficiency and sound reduction index with high spectral resolution [46], including the effect of the finiteness of the test object on the radiation efficiency and sound reduction index $[47,48]$.

As mentioned above, in practice, ETICS are applied mainly on building facades. However, in specific cases, ETICS are also implemented for thermal insulation of ceilings and internal walls. In the following, we report on the characterization of a façade wall in laboratory circumstances. The sound reduction improvement index $\Delta R$ expresses in our study the improvement of the sound insulation index $R$ thanks to ETICS and is used to objectively quantify the influence of ETICS on the acoustic insulation performance of walls. Finally, the vibrometry results for $\Delta R$ are also compared with microphone measurements and analytical prediction model results.

\section{Experimental Approach}

A massive brick wall was characterized before (Wall 1) and after (Wall 2) refurbishment with ETICS and tested in a building acoustics laboratory. The basic wall consisted of ceramic hollow bricks ( $220 \mathrm{~mm}$ ) filled by concrete of the class C12/15. The wall was plastered by lime plaster with a thickness of $15 \mathrm{~mm}$ (Figure 1a). The total surface mass density of the wall was $m_{1}=375 \mathrm{~kg} / \mathrm{m}^{2}$. The ETICS addition in Wall 2 consisted of a layer of adhesive mortar $(1.5 \mathrm{~mm})$, a layer of (thermally insulating) dense mineral wool $\left(35 \mathrm{~mm} ; \mathrm{s}^{\prime}=15 \times 10^{6} \mathrm{~N} / \mathrm{m}^{3} ; \rho=112.7 \mathrm{~kg} / \mathrm{m}^{3} ; r=18.3 \mathrm{kNs} / \mathrm{m}^{4}\right)$ and a layer of lime plaster $\left(25 \mathrm{~mm} ; m_{2}=28 \mathrm{~kg} / \mathrm{m}^{2}\right)$. 

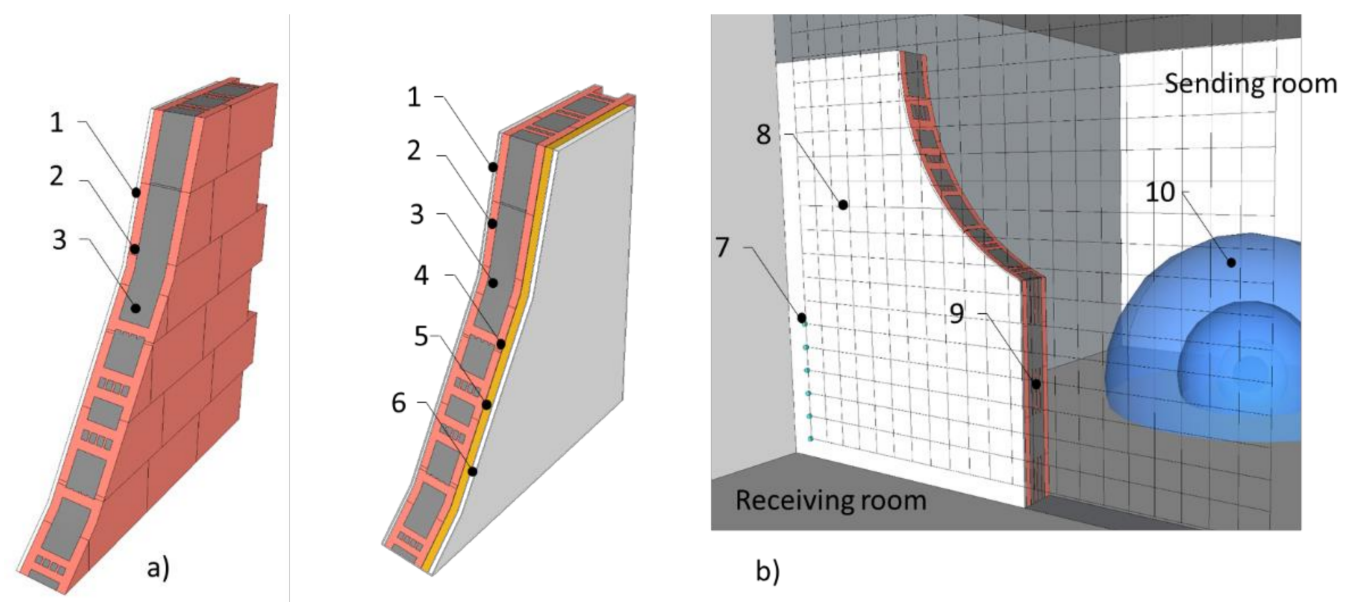

b)

Figure 1. (a) Composition of the measured walls. Wall 1, without (left) and Wall 2, with ETICS (right). (b) Schematic representation of accelerometer locations used for vibrometry: (1) lime plaster (15 mm); (2) hollow brick (220 mm); (3) concrete (200 mm); (4) adhesive mortar (1.5 mm); (5) mineral wool (35 mm); (6) lime plaster (25 mm); (7) B\&K acceleration receivers $6 \times$; (8) the measurement grid of $22 \times 18$ points with spacing of $150 \mathrm{~mm}$; (9) the cross-section of the test wall; and (10) acoustic excitation.

The goal of the measurements, which took place in the transmission suite according to ISO 10140-5 [27], was to determine the effect of ETICS implementation on the sound reduction index of a massive wall. The volume of the transmission rooms was $V_{\text {sending }}=50.2 \mathrm{~m}^{3}$ and $V_{\text {receiving }}=53 \mathrm{~m}^{3}$. The Schroeder frequency of the rooms was approximately $f_{\text {Schroeder }} \approx 330 \mathrm{~Hz}$. The surface of the test wall element, which fully filled the test opening, was $S=10.7 \mathrm{~m}^{2}$. Pink noise of $97 \mathrm{~dB}$ in each $1 / 3 \mathrm{rd}$ octave band was used to acoustically excite the test walls. The sound transmission was determined by both microphone and vibrometry measurements.

\subsection{Determination of Airborne Sound Insulation Based on ISO 10140-2}

The airborne sound insulation $R(\mathrm{~dB})$ was determined in accordance to ISO 10140-2 [26], by calculation of the sound pressure level difference $D(\mathrm{~dB})$ from the spatially averaged sound pressure level measured in the sending room and receiving room $\left(L_{p 1}-L_{p 2}\right)$, corrected with a term to account for the amount of sound absorption in the receiving room:

$$
R=L_{p 1}-L_{p 2}+10 \log \left(\frac{S}{A}\right)=D+10 \log \left(\frac{S \cdot c \cdot T}{55.26 \cdot V}\right)
$$

where $D(\mathrm{~dB})$ is sound pressure level difference, $c\left(\mathrm{~ms}^{-1}\right)$ is the speed of sound in air, and $T(\mathrm{~s})$ and $V$ $\left(\mathrm{m}^{3}\right)$ are the reverberation time and volume of the receiving room (RR), respectively. $A\left(\mathrm{~m}^{2}\right)$ and $S\left(\mathrm{~m}^{2}\right)$ are the receiving room absorption area and tested wall area, respectively.

\subsection{Determination of Airborne Sound Insulation Based on Vibrometry}

In view of the effect ETICS application plays mainly at low frequencies, and of the reduced accuracy of microphone-based measurements below $100 \mathrm{~Hz}$, we also assessed the sound insulation of the two test configurations by means of a vibrometry-based approach [44].

The measuring equipment for the vibrometry tests consisted of 6 accelerometers of Brüel \& Kjaer type 4370 , of which one was used as a reference. The signals, amplified by Brüel \& Kjaer type 2635 charge amplifiers, were simultaneously recorded with an 8-channel Sinus Soundbook analyzing system, with Samurai 1.7.14 software. For calibration of the complete measuring chain, an acceleration calibrator type MMF VC10 was used. 
The sound power radiated by the test wall in the receiving room due to transmission of sound coming from the sending room can be calculated by an approach that was elaborated in [44,49-51]. Based on the measured normal velocity $v_{n}\left(\mathbf{r}_{s}, \omega\right)$ of the vibrating surface at positions $\mathbf{r}_{s}$ on the wall, the acoustic pressure $p(\mathbf{r}, \omega)$ at position $r$ in the receiving room (denoted by distance $\underline{R}=\left|\mathbf{r}-\mathbf{r}_{s}\right|$ ) can be calculated by

$$
p(\mathbf{r}, \omega)=\frac{i \omega \rho}{2 \pi} \iint_{S} v_{n}\left(\mathbf{r}_{S}, \omega\right) \frac{e^{-i k \underline{R}}}{\underline{R}} d S
$$

where $S$ is the area of the vibrating wall $S, \rho$ is the density of air, $\omega$ is the angular frequency and $c$ is the speed of sound in air. Based on calculated pressure $p\left(\mathbf{r}_{s}, \omega\right)$ and the measured normal velocity $v_{n}\left(\mathbf{r}_{\boldsymbol{s}}\right.$, $\omega)$, the active acoustic intensity $I$ along the surface and the total radiated active sound power $P$ can be computed as:

$$
\begin{gathered}
I\left(\mathbf{r}_{S}, \omega\right)=\frac{1}{2} \operatorname{Re}\left[p\left(\mathbf{r}_{S}, \omega\right) v_{S}^{*}\left(\mathbf{r}_{S}, \omega\right)\right] \\
P(\omega)=\iint_{S} I\left(\mathbf{r}_{S}, \omega\right) d S
\end{gathered}
$$

where * denotes complex conjugate, and Re denotes the real part. The resulting sound power level $L_{W}=10 \log _{10}\left(P / P_{r e f}\right)$, with $P_{\text {ref }}=10^{12} \mathrm{~W} / \mathrm{m}^{2}$, is independent of the acoustic response of the receiving room and, in contrast with microphone-based measurements, not affected by room acoustic aspects of the receiving room, such as reverberation and mode formation. In the microphone-based ISO 10140-2 approach, sound reflections and reverberation can be adequately considered using the reverberation time in the calculation of the sound reduction index Equation (1). In principle, the non-uniformity of the measured acoustic field in the receiving room is also considered by averaging receiving room sound pressure values over multiple positions, and by exploiting the fact that, in $1 / 3$ octave band averaging, strongly frequency dependent spatial non-uniformities of room acoustic modes are cancelled out. However, the latter averaging effect is cumbersome at low frequencies, when the modal density becomes very low and the spatially slowly varying pressure field of modes is difficult to sample. This violation of the acoustic diffuseness assumption makes the measured sound power radiated into the room using microphones strongly dependent upon the room size and shape at low frequencies, and thus varying from laboratory to laboratory. The value of $L_{W}$ obtained by means of the Rayleigh integral approach does not suffer from this issue and, by means of the relation between the radiated sound power $P_{\text {rad }}\left(\right.$ Watt), the intensity $I\left(\right.$ Watt $/ \mathrm{m}^{2}$ ) and root mean square sound pressure $p_{r m s}(\mathrm{~Pa})$ of a plane source with surface $S\left(\mathrm{~m}^{2}\right), P_{\text {rad }}=I S=\frac{p_{r m s}^{2} S}{Z} S$, with $\mathrm{Z}$ the specific acoustic impedance of air, so that $p_{r m s}=\sqrt{P_{\text {rad }} Z / S}$, it can be used as follows to determine the sound reduction index:

$$
R=L_{p 1}+10 \log S-6-L_{W}
$$

Note that this estimate of the airborne sound insulation $R$ is independent of the reverberation time of the receiving room. However, for comparing with microphone-based measurements of $R$, the following additional correction factors, proposed by Vorländer and Waterhouse, should be considered [52,53].

$$
R=L_{p 1}+10 \log S-K_{d}-L_{W}+K_{a}+K_{w}+C_{1}+C_{2}
$$

where $C_{1}$ and $C_{2}$ are meteorological correction factors [54]. $K_{\mathrm{a}}$ involves high frequencies correction factors [53] and $K_{W}$ the Waterhouse correction for low frequencies, which includes effects of the boundaries of the receiving room [52]. $K_{d}$ is the random-incidence factor (directivity factor), which corrects for effects of the radiated acoustic near field.

In the classical procedure to determine the airborne sound insulation $R$ by means of Equation (1), the sound pressure level is measured by means of microphones. For purpose of comparison, the effective sound pressure in the actual receiving room is determined from the sound power levels 
as computed by the Rayleigh integral, considering the measured reverberation time of the receiving room, using the expression

$$
L_{p 2}=L_{w}-10 \log \left(\frac{A}{A_{0}}\right)-4.34 \frac{A}{S}-10 \log \left(1+\frac{c S}{8 V f}\right)-C_{1}-C_{2}+6
$$

which may also be expressed as

$$
L_{p 2}=L_{w}-10 \log A-K_{a}-K_{w}-C_{1}-C_{2}+K_{d}
$$

where $A_{0}=1 \mathrm{~m}^{2}$ is the reference area.

Vibration measurements were made by scanning the positions of 5 accelerometers on a grid with spacing of $15 \mathrm{~cm}$ on the receiving side of the wall (which was built on the side of the sending room (Figure 1b), while recording simultaneously the signal of an accelerometer at a reference position in one of the corners of the wall. The accuracy of interpolating deflection shapes depends on the number of samples per wavelength. According to the Nyquist-Shannon sampling theorem, the used spacing of $\mathrm{g}=15 \mathrm{~cm}$ allows to accurately sample structural waves with wavelengths up to $4 \mathrm{~g}=60 \mathrm{~cm}$, which, based on the velocity dispersion curves in Figure 4, corresponds with a frequency of $1250 \mathrm{~Hz}$ (bending wave velocity $955 \mathrm{~m} / \mathrm{s}$ ). Results obtained by airborne exciting the sending room with pink noise can thus be expected to be reliable till about $1250 \mathrm{~Hz}$.

\subsection{Determination of ETICS Induced Weighted Sound Reduction Index Improvement}

Different approaches have been proposed to determine the effect of the implementation of ETICS on the sound reduction index, $\Delta R_{W}[12,13]$.

For the commonly used ETICS walls consisting of mineral wool glued by adhesive mortar on $40 \%$ of the wall surface area (commonly used in practice), and plaster layers with thickness and density so that the resonance frequency is below $125 \mathrm{~Hz}$, Weber [13] reported the following empirical relationship for the effect of ETICS on the acoustic insulation in terms of a single number rating:

$$
\Delta R_{w}=-35.9 \log \left(\frac{1}{2 \pi} \sqrt{s^{\prime}\left(\frac{1}{m_{1}^{\prime}}+\frac{1}{m_{2}^{\prime}}\right)}\right)+82.4=-35.9 \log \left(f_{0}\right)+82.4
$$

Weber also proposed a predictive model for the spectrum of the ETICS induced effect on the sound reduction index:

$$
\Delta R=20 \log \left(\sqrt{\frac{\left(1-\left(\frac{f}{f_{0}}\right)^{2}\right)^{2}+4\left(\frac{\eta}{2}\right)^{2}\left(\frac{f}{f_{0}}\right)^{2}}{1+4\left(\frac{\eta}{2}\right)^{2}\left(\frac{f}{f_{0}}\right)^{2}}}\right)
$$

where $\eta(-)$ is the structural damping. Equation (8) holds for frequencies above $f_{0}(\mathrm{~Hz})$, the resonance frequency. For frequencies below $f_{0}$, the model assumes no effect: $\Delta R_{W}=0 \mathrm{~dB}$. Equation (8), which holds for frequencies below the coincidence frequency of the basic wall, $f_{c}$, predicts an increase of $\Delta R_{W}$ with $12 \mathrm{~dB}$ per octave.

\section{Results}

\subsection{Assessment in Accordance to ISO 10140}

Figure 2 shows the sound insulation spectrum of the two walls as obtained by ISO 10140-2. The dip around $f_{0} \approx 125 \mathrm{~Hz}$ in the ETICS treated wall, caused by the reduced acoustic impedance (mismatch with the air) of the multilayer at resonance, agrees with Equation (9), using the following known values 
for the involved material properties: $m_{1}=375 \mathrm{~kg} / \mathrm{m}^{2}, m_{2}=28 \mathrm{~kg} / \mathrm{m}^{2}$, and $\mathrm{s}^{\prime}=15 \mathrm{MN} / \mathrm{m}^{3}[13,42]$. In addition, other features of the ETICS effect are as expected. On the one hand, below resonance, the added mass of the plaster and mineral wool layer is too small to significantly increase the sound insulation. On the other hand, above the dip, the addition of a (thin) mass layer and cavity leads to a dual mass law behavior of $12 \mathrm{~dB}$ /octave-behavior, in contrast with the single mass law behavior of $6 \mathrm{~dB}$ /octave-behavior of the bare Wall 1. Both spectra also show a dip at $f_{c} \approx 160 \mathrm{~Hz}$ due to the coincidence effect. However, in the case of ETICS Wall 2, the mass-spring-mass dip is clearly dominant. Figure 2 illustrates that, despite the drastic differences between the insulation curves of both walls, the effect on the respective shifted "matching" reference curves is pretty small.

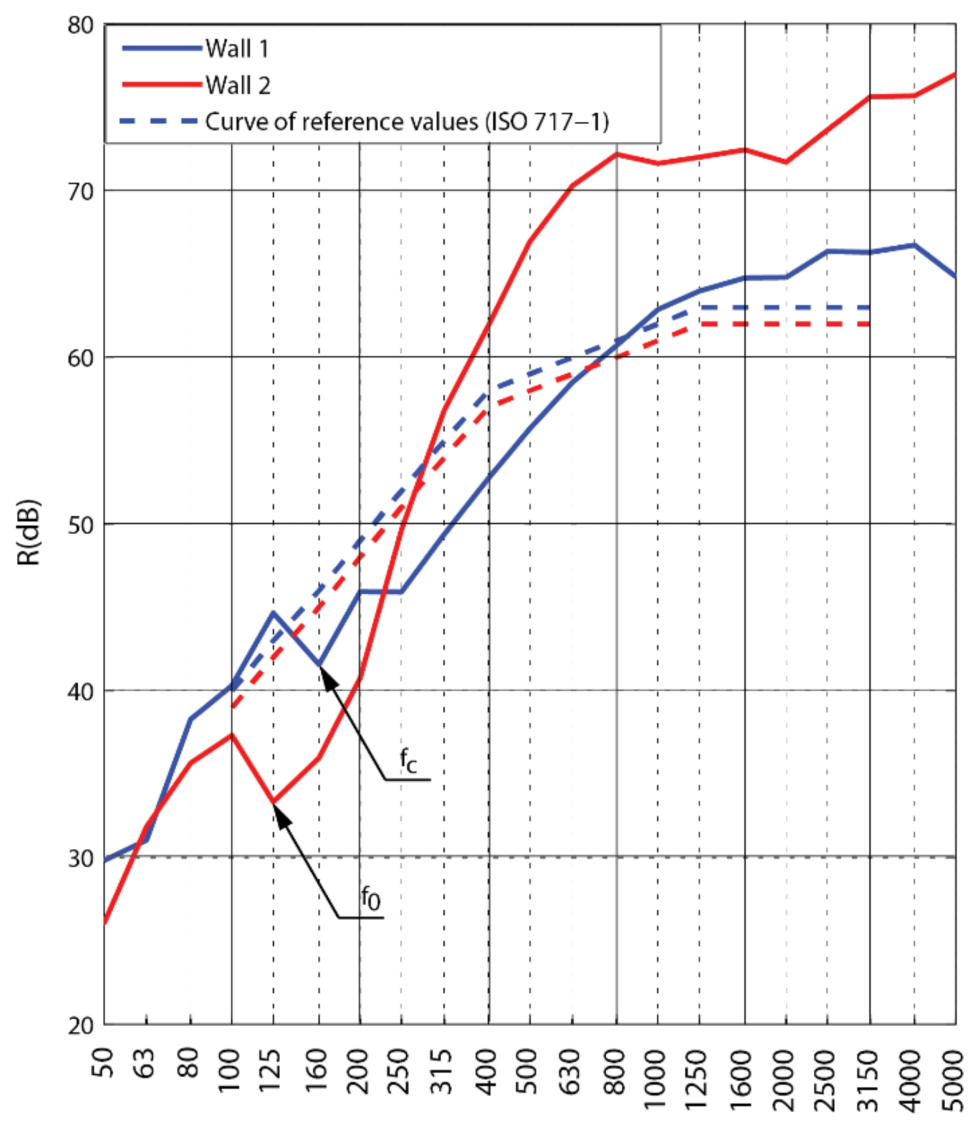

$\mathrm{f}(\mathrm{Hz})$

Figure 2. Airborne sound insulation curves of Walls 1 and 2 obtained by ISO 10140-2, together with the respective shifted reference curves [26].

In theory, the resonance frequency of an ETICS system can be roughly estimated by [42]:

$$
f_{0}=\frac{1}{2 \pi} \sqrt{s^{\prime}\left(\frac{1}{m_{1}^{\prime}}+\frac{1}{m_{2}^{\prime}}\right)}
$$

where $m_{1}$ is a total mass per unit area of Wall $1\left(\mathrm{~kg} \cdot \mathrm{m}^{-2}\right) ; m_{2}$ is mass per unit area of the used plaster $\left(\mathrm{kg} \cdot \mathrm{m}^{-2}\right)$; and the "spring" of the system, (i.e., mineral wool placed in the cavity between the two walls) is characterized by its dynamic stiffness $s^{\prime}\left(\mathrm{N} \cdot \mathrm{m}^{-3}\right)$ measured in accordance with EN 29052-1 [55]. Typical values are given in the Section 2 of this article. In addition to the properties of materials used for ETICS, the sound insulation is also affected by aspects of workmanship, e.g., related to how the insulation slabs are mounted onto the supporting wall. 
Consequently, the effect on the single number ratings (Table 1) is quite small: application of ETICS in this case deteriorates $R_{W}$ (ISO 717-1 [20]) by $1 \mathrm{~dB}$. Considering spectrum adaptation terms $\left(C ; C_{t r}\right)$, the single number sound insulation decreases by amounts between 2 and $4 \mathrm{~dB}$.

Table 1. Comparison between ISO 10140-2 based single number ratings.

\begin{tabular}{cccc}
\hline Symbol & Wall 1 ISO & Wall 2 ISO & $\Delta \boldsymbol{R}_{\boldsymbol{w}}$, ISO \\
\hline$R_{w}(\mathrm{~dB})$ & 59 & 58 & -1 \\
$C(\mathrm{~dB})$ & -2 & -3 & -1 \\
$C_{t r}(\mathrm{~dB})$ & -6 & -9 & -3 \\
$C_{50-3150}(\mathrm{~dB})$ & -3 & -4 & -1 \\
$C_{50-5000}(\mathrm{~dB})$ & -2 & -3 & -1 \\
$C_{100-5000}(\mathrm{~dB})$ & -1 & -3 & -2 \\
$C_{t r, 50-3150}(\mathrm{~dB})$ & -10 & -12 & -2 \\
$C_{t r, 50-5000}(\mathrm{~dB})$ & -10 & -12 & -2 \\
$C_{t r, 100-5000}(\mathrm{~dB})$ & -6 & -9 & -3 \\
\hline
\end{tabular}

\subsection{Assessment by Vibrometry Approach}

Using vibrometry, by analyzing operational deflection shapes (ODSs), the radiated sound power $(P(W))$ and the radiation efficiency $(\sigma(-))$, additional information can be obtained about the factors that affect the sound insulation of the considered walls. Some of the ODSs, determined as frequency response functions between accelerometer signals obtained on measurement grid and the reference signal, are shown in Figure 3. Figure 3 shows operational deflection shapes of the two structures at the lowest structural resonance frequencies, as well as the spectrum of the velocity level $L_{v}\left(\mathrm{~dB}\right.$ re ms${ }^{-1}$; $v_{0}=5 \times 10^{-8} \mathrm{~m} / \mathrm{s}$ ). The peaks in the spectrum of the velocity level $L_{v}$ indicates resonances occurrence. By evaluating the response for each point of the wall surface, the ODS was plotted. The lowest natural frequency $f_{(1 ; 1)}$ is about $67 \mathrm{~Hz}$. Although the phenomenon of coincidence is not related to a structural resonance, the velocity spectrum shows a peak at $f_{c} \approx 160 \mathrm{~Hz}$, as a result of the increased coupling with the vibration exciting airborne waves at and above that frequency. The ETICS resonance appears as a peak in the $L_{v}$ spectrum at about $f_{0} \approx 119 \mathrm{~Hz}$. At $f \approx 230 \mathrm{~Hz}$, the $L_{v}$ spectra of Wall 1 and Wall 2 are equal, which is consistent with the equality at that frequency of the sound insulation spectra.

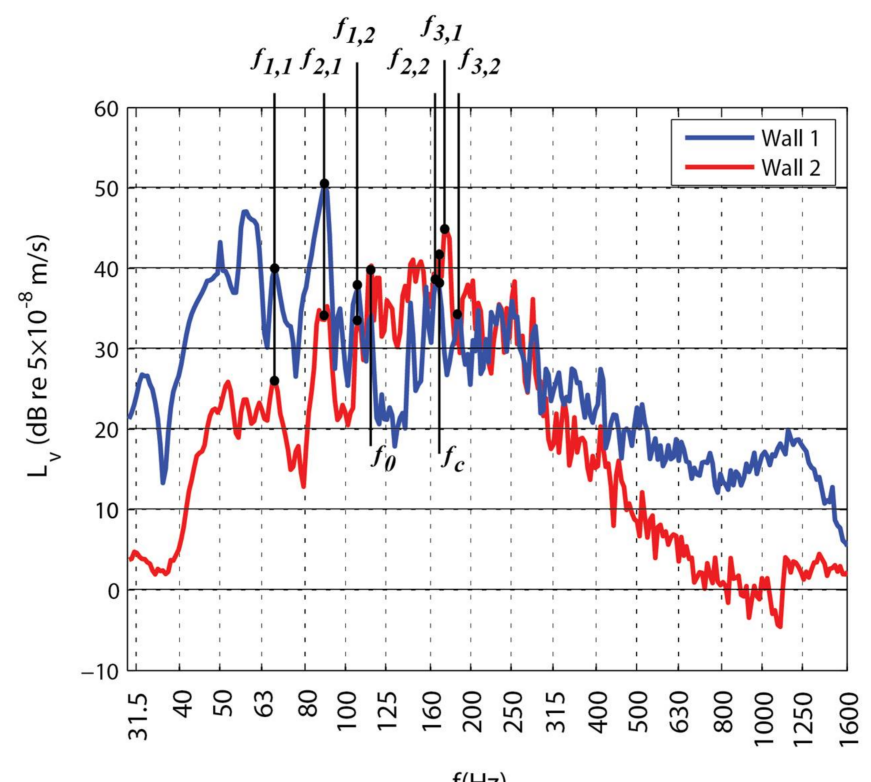

$\mathrm{f}(\mathrm{Hz})$

a)

Figure 3. Cont. 


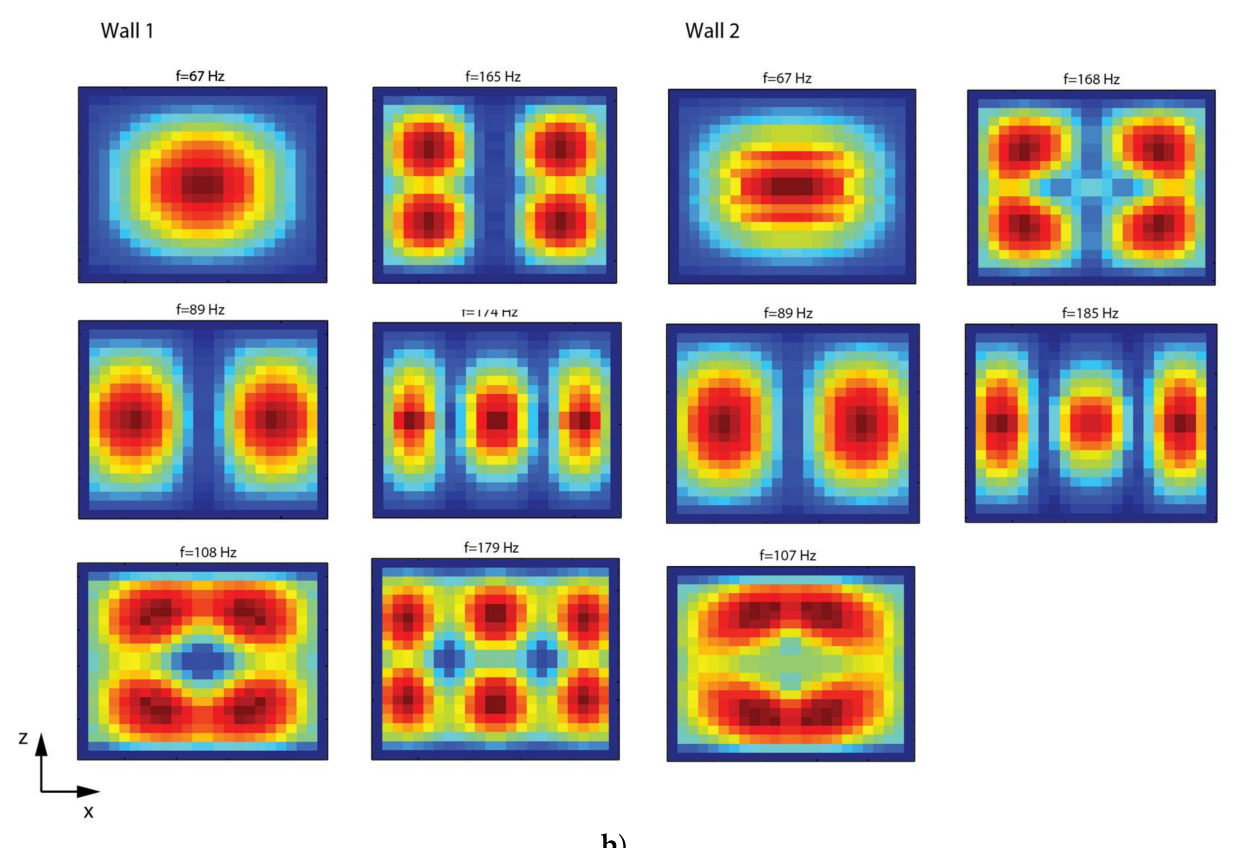

b)

Figure 3. (a) Mean value of velocity response (in $\mathrm{dB}$ ) on the surface in narrow band spectrum; and (b) operational deflection shapes (ODSs) visualization and mean value of measured velocity on the wall surface in the RR.

Exploiting the rectangular symmetry of the wall, it was sufficient to measure the vibrational response of the wall in only one quadrant by means of accelerometers. The response of the other quadrants was determined by mirroring the maps of the measured quadrant along the horizontal and vertical axis and along the center point. In this manner, the measurement effort could be reduced, with the drawback that this approach is only valid for the lowest eigenmodes (natural frequencies) of the wall. Having measured on a grid of $9 \times 11$ measurement points in one quadrant, a full dataset of $18 \times 22$ was obtained in that manner. The operational deflection shapes thus obtained are shown in Figure 3. Vibration amplitudes $a_{n}(x, y, \omega)$ are mapped along a grid consisting of $18 \times 22$ points, with an interspacing of $15 \mathrm{~cm}$ between the measurement points. For every frequency component of the measured responses, a two-dimensional spatial Fourier transform was taken, to arrive at the wavenumber domain $\left(k_{x}, k_{y}\right)$ :

$$
a_{n}\left(k_{x}, k_{y}, \omega\right)=\mathcal{F} \mathcal{F}\left\{a_{n}(x, y, \omega)\right\}
$$

where $\mathcal{F}_{x}$ and $\mathcal{F}_{x}$ represent a spatial Fourier transform in $\mathrm{x}$ - and y-direction, respectively. Although other methods exist, such as Prony's method or the wavenumber fit method [56], the spatial Fourier transform is the easiest approach to assess the wavenumbers present in the vibrating wall at each angular frequency $\omega$.

Spatial windowing techniques are usually employed to reduce possible leakage of the data [57]. However, in the present case, the wall was mounted in a heavy test-setup, which enforced the vibrations at the edges of the spatial domain to zero. This in itself reduced the possible occurrence of leakage, and thus a spatial window was not needed in this case.

The thus obtained wavenumbers $k=\operatorname{sqrt}\left(k_{x}^{2}+k_{y}^{2}\right)$ are shown versus frequency in Figure $4 \mathrm{a}$. Next, the velocity $c_{B}$ of the bending waves along the supporting wall was obtained via $c_{B}=2 \pi f / k$. Figure $4 \mathrm{~b}$. shows that the bending wave velocity exceeds the speed of sound in air for frequencies starting from and above $160 \mathrm{~Hz}$, which is consistent with the coincidence induced dip in the in the insulation curve in Figure 2. 
Assuming the brick wall can be approximated by means of Kirchhoff's thin shell theory, the bending wave speed can be estimated with the following relation [56]:

$$
c_{B}=\left(\frac{E h^{3}(2 \pi f)^{2}}{12 m\left(1-v^{2}\right)}\right)^{1 / 4}
$$

with $h=0.260 \mathrm{~m}$ the total thickness, and $m=403 \mathrm{~kg} / \mathrm{m}^{2}$ the total mass. Assuming ad hoc a typical value for Poisson's ratio, $v=0.3$, the effective Young's modulus $E$ was found to be $4.88 \mathrm{GPa}$. For higher frequencies, the assumption of a thin shell is no longer valid. However, for frequencies near the coincidence frequency (approximately $160 \mathrm{~Hz}$ ), the structural wavelength of flexural waves in the structure of interest (@160 Hz: $k \cong 3 \mathrm{rad} / \mathrm{m}$, thus $\lambda \cong 2 \pi / 3 \cong 2 \mathrm{~m}$ ) was still large as compared to the thickness of the wall $(0.26 \mathrm{~m})$. This justifies the use of Kirchhoff's thin shell theory in the lower frequency range, and thus the estimate of Young's modulus in this frequency range.

In the following, we further exploit the detailed information yielded by vibrometry analysis, to assess the radiation efficiency of the ETICS structure, as well as the insulation behavior in the frequency range that is too low to be reliably addressed by microphone measurement, but relevant for subjective perception. The radiation efficiency is defined as the ratio of the acoustic power radiated by the structure, to the power radiated by a reference system that consists of a uniformly vibrating baffled piston of the same area $S$ and mean velocity [44]:

$$
\sigma(\omega)=\frac{\widetilde{P}(\omega)}{\rho c S\left\langle\widetilde{v}_{n}^{2}(\omega)\right\rangle}
$$

where the $<>$ operator denotes spatial averaging over the surface of the structure and $v_{n}$ is the component of the vibrational velocity normal to the surface. Vibrational patterns of layered structures are not spatially uniform, and the polarization of the motion is not fully perpendicular to the surface of the layers. Moreover, the match between the wavelength of bending waves and the one of acoustic waves in the air is frequency dependent. The radiation efficiency reflects to what extent these aspects are lowering or raising the coupling of the structural vibration energy into airborne radiated acoustic energy in the sending room and vice versa in the receiving room.

Equation (12) can be evaluated using the measured, spatially averaged vibration levels $\left\langle v_{n}{ }^{2}\right\rangle$ as extracted from the accelerometer signals, and the sound power $P(\omega)$ as calculated from those via Equation (5). The results are shown in Figure 5 for both walls. The local maximum at ca. $67 \mathrm{~Hz}$ for both walls can be associated with the first natural mode of the structural vibration spectrum of the supporting wall. The values of the frequency $f_{1,1}$ are consistent with expectations based on the bending velocity dispersion curve as determined in Figure 4 and Equation (10): setting the bending wavelength components $\lambda_{x} / 2=L_{x}=3.49 \mathrm{~m}, \lambda_{y} / 2=L_{y}=3.09 \mathrm{~m}$, using $k=\left(k_{x}{ }^{2}+k_{y}{ }^{2}\right)^{1 / 2}$, with $k_{x}=2 \pi \pi / \lambda_{x}$ and $k_{y}=2 \pi / \lambda_{y}$, and inserting the best fitting dispersion curve $c_{B}(f)=\mathrm{a} \sqrt{ } f$, with $\mathrm{a}=38 \mathrm{~m} / \mathrm{s}^{3 / 2}$ in $k=2 \pi f / c_{B}(f)$, the expected structural mode frequency is $f_{1,1}=(\mathrm{a} k /(2 \pi))^{2}=(\mathrm{a} / 2)^{2}$ $\left(L_{x}{ }^{-2}+L_{y}{ }^{-2}\right)=67 \mathrm{~Hz}$. Below this frequency, the radiation efficiency increases $12 \mathrm{~dB} /$ octave, which is in accordance with theoretical behavior of a wall vibrating in its fundamental 1-1 mode (Fahy [50]). The width of the structural vibration induced maximum in the radiation efficiency is determined by the structural damping. The behavior below $f_{1,1}$ and above $f_{c}$ are known to be independent of the loss factor $[45,58]$. Apart from this feature, the radiation efficiency rises to the coincidence (critical) frequency region, which, consistent with the previous analysis, sets in around $160 \mathrm{~Hz}$. 


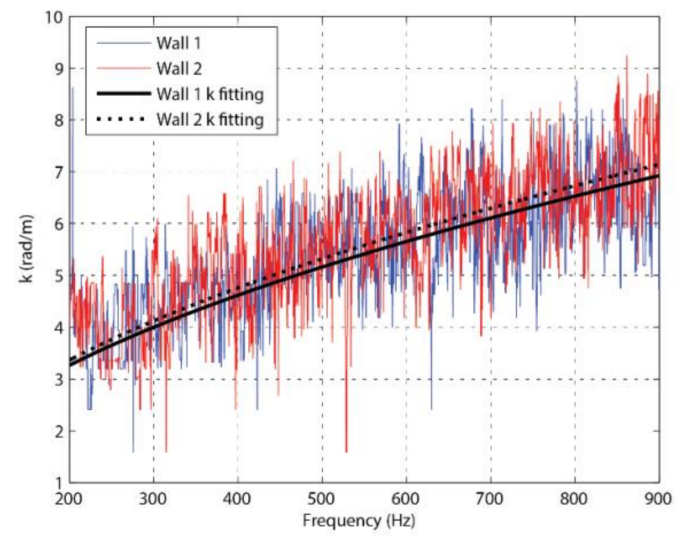

a)

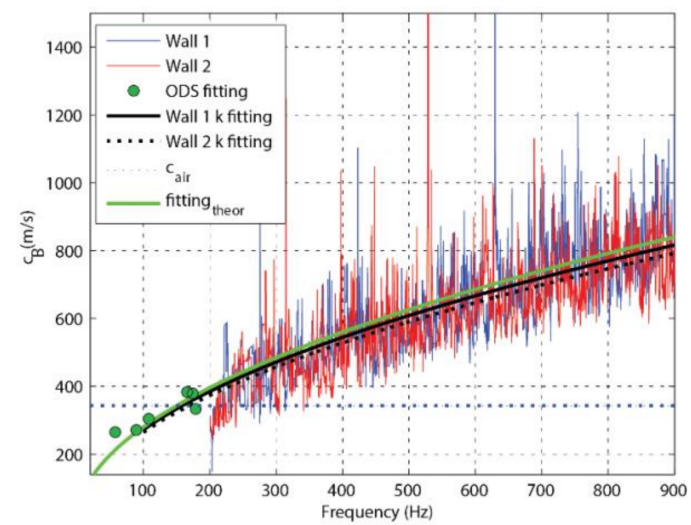

b)

Figure 4. Dispersion data obtained by ODS and 2D dispersion data fitting approaches: mean of the wave number (a); and wave propagation velocity (b) dispersion curve data and best fit for Wall 1 and Wall 2. The symbols were obtained by estimating the wavelength of the modes from the ODS. The dotted line in (b) depicts the speed of sound in air. The crossing point between the dispersion curve and the dotted line indicates where coincidence occurs.

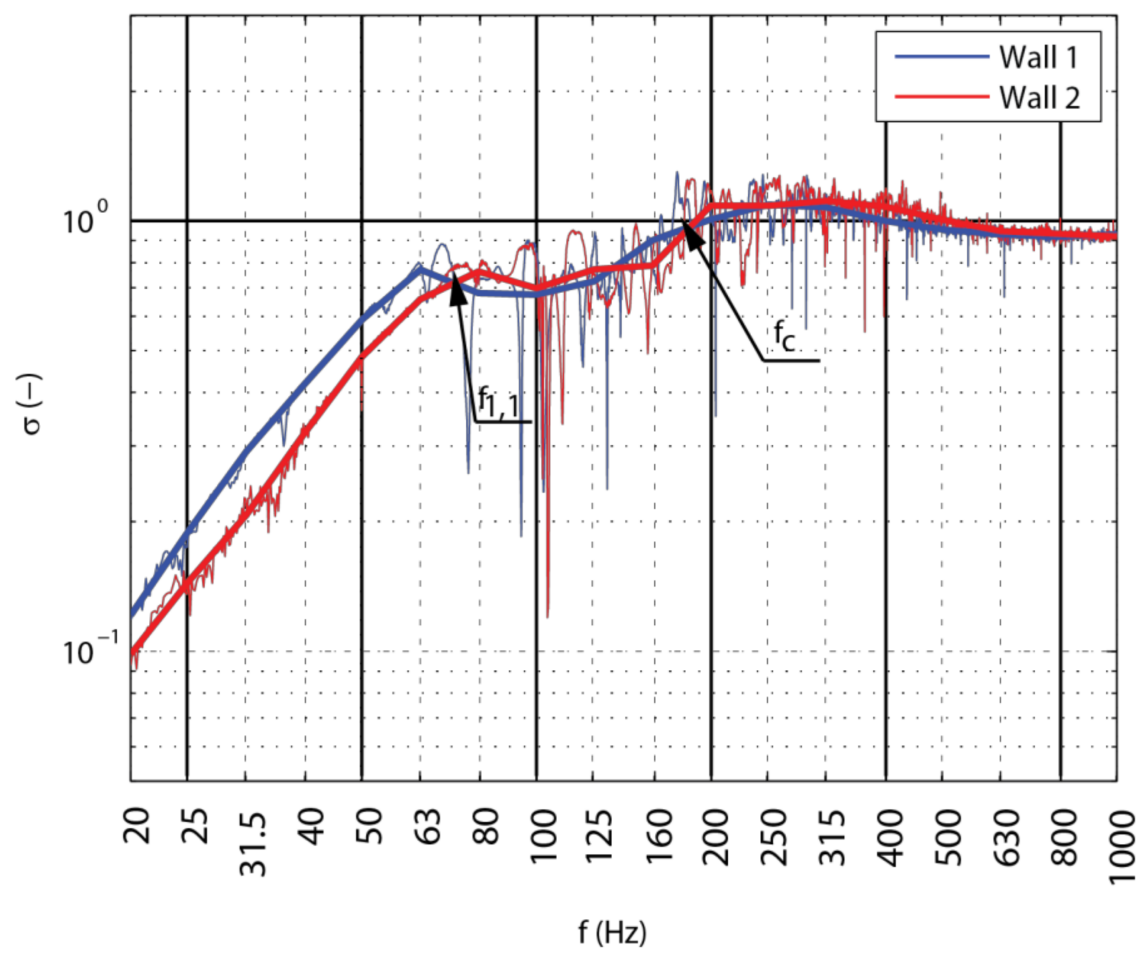

Figure 5. Spectrum of the radiation efficiency, extracted from the pattern of the measured normal velocity component and the calculated sound power.

As explained in Section 2.2, the radiated sound power spectrum calculated from the ODS at different frequencies (Equation (5)) is independent of the room acoustic features of the receiving room and is thus an adequate measure for the pure acoustic insulation characteristics of the wall structures of interest. The availability of this result together with the insulation spectrum as obtained by classical microphone measurements have motivated us to compare both and thus to assess in detail 
the effects of room acoustics on the sound characteristics in the receiving room and on the results of classical measurements.

\subsection{Sound Reduction Improvement}

Figure 6 shows, for both walls, a comparison between the radiated sound pressure level measured by microphones (ISO 10140-2, denoted in the legend as $L_{\mathrm{p}, \mathrm{RR}(\mathrm{Mic})}$ ) and calculated from ODSs (denoted in the legend as $\left.L_{\mathrm{p}, \mathrm{RR}(\mathrm{Rayl})}\right)$.

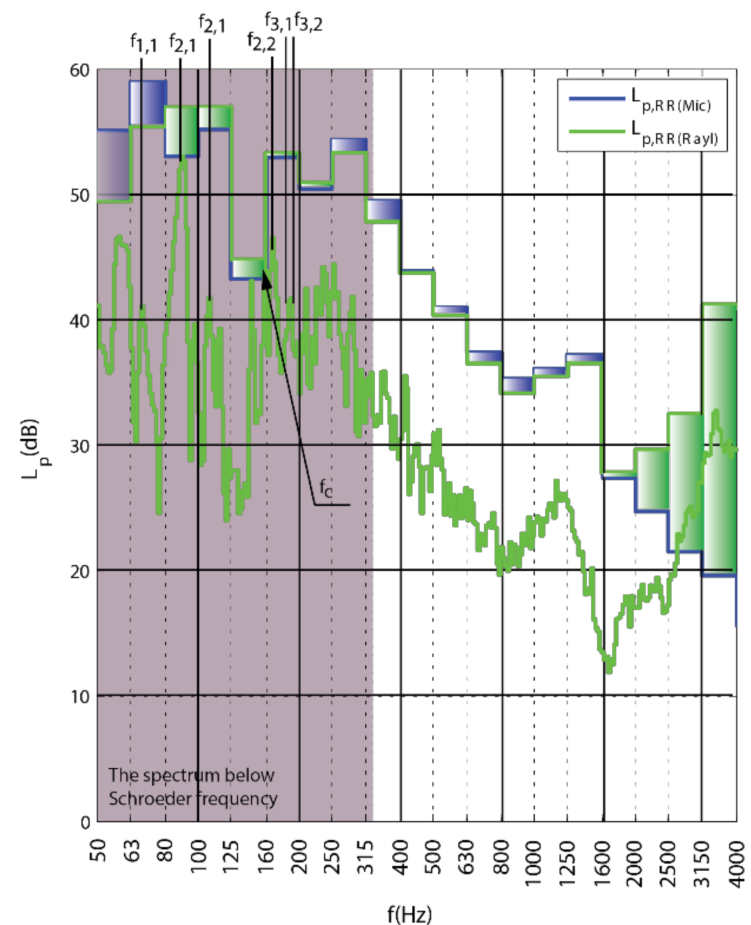

a)

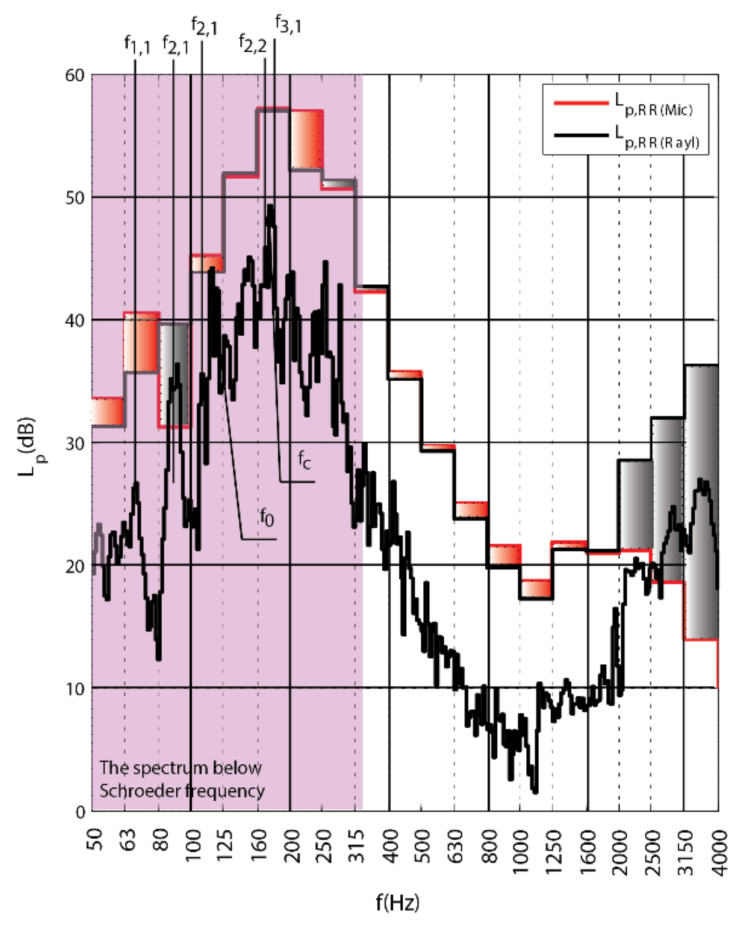

b)

Figure 6. Sound pressure level $\left(L_{\mathrm{p}}\right)$ spectrum in the receiving room during measurements: Wall 1 (a); and Wall 2 (b). The area highlighted in purple indicates the spectrum below the Schroeder frequency. Blue and red curves express the $L_{\mathrm{p}}$ measured by standardized microphone approach in $1 / 3$ rd octave spectrum. Green and black curves are the results of $L_{\mathrm{p}}$ achieved by vibrometry data processing in $1 / 3$ rd and $1 / 48$ th octave bands. $f_{\mathrm{c}}$ is the coincidence frequency of the wall; $f_{0}$ is the ETICS resonance frequency; and $f_{i, I}$ is the wall structural modes (i.e., $f_{1,1}$ is the first wall natural mode frequency).

In accordance with ISO 10140-2, the microphone-based results were corrected for room acoustic effects by application of the factor $-10 \cdot \log _{10}(\mathrm{~A})$ in Equation (1). Nevertheless, due to the non-diffusiveness of the room below the Shroeder frequency of the receiving room $(330 \mathrm{~Hz})$, differences in the $1 / 3$ th octave $R$-spectrum with the ODS based spectrum, amount up to $8 \mathrm{~dB}$ (at $80 \mathrm{~Hz}$ ). For higher frequencies, microphone measurements are not affected by room acoustics, by virtue of the high density per frequency band of room acoustic modes, which allows cancelling out their effect by spatial and frequency averaging. The accuracy of deflection shapes interpolation is related to the number of the samples per specific wave length. Vibrometry measurements however become less reliable, as they are based on a spatial scan along the wall with a finite grid spacing $\mathrm{g}=15 \mathrm{~cm}$. According to the Nyquist-Shannon sampling theorem, this only allows accurately sampling structural waves with wavelengths up to $4 \mathrm{~g}=60 \mathrm{~cm}$, which, based on the velocity dispersion curves in Figure 4, corresponds with a frequency of $1250 \mathrm{~Hz}$ (bending wave velocity $955 \mathrm{~m} / \mathrm{s}$ ).

Considering the reduced accuracy of microphone and accelerometer-based measurements at low and high frequencies, respectively, we have taken the best of both and retained data above and below 
$1250 \mathrm{~Hz}$ for microphone and accelerometer-based measurements, respectively, thus constructing the combined spectra in Figure 7. Based on the resulting combined $R$-spectrum, the $R_{W}$ value of Wall 1 is $1 \mathrm{~dB}$ lower than based on the microphone-based data alone (Table 2). The spectrum adaptation terms $C$ and $C_{t r}$ are both 1-2 dB lower. The complementarity between the microphone and accelerometer-based results allows assessing the effect of ETICS on the sound insulation spectrum in an extended frequency range, as shown by $\Delta R=R_{\text {wall } 2}-R_{\text {wall } 1}$ in Figure 8 . The most prominent ETICS induced effect on the sound insulation curve occurs below $250 \mathrm{~Hz}$, where the ETICS resonance causes a large dip in the frequency spectrum. In this range, the microphone results are affected by the spatial non-uniformity of the pressure level pattern of room acoustic modes [44], so that the $\Delta R$ values extracted from vibrometry measurements can be considered as the more reliable.

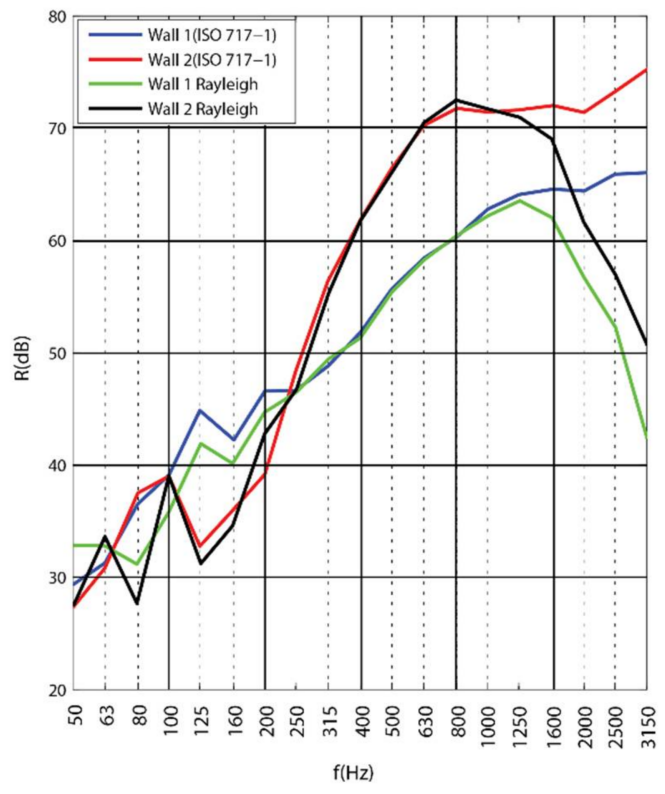

a)

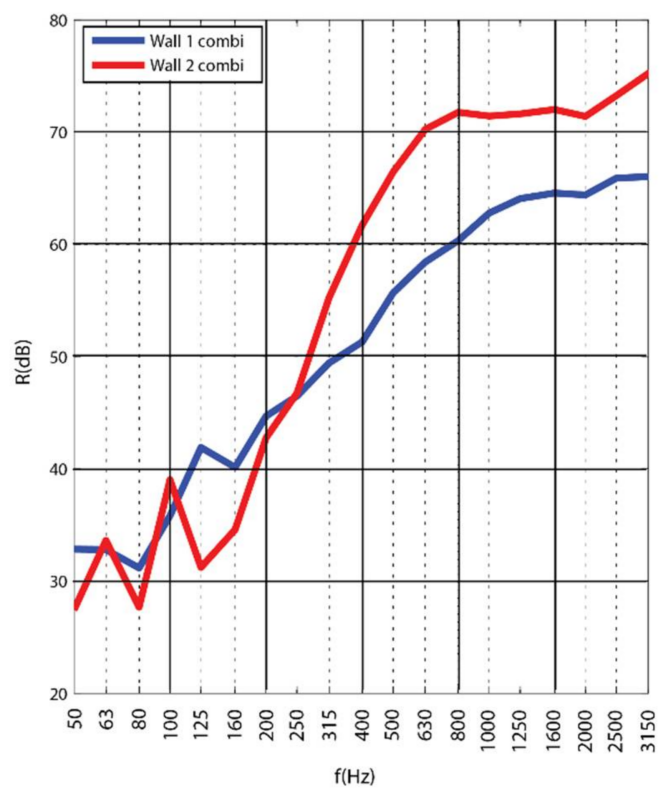

b)

Figure 7. Spectra of the sound reduction index of Walls 1 and 2. (a) Comparison between the two measurement approaches in 1/3rd octave bands. Green and black lines: sound insulation curves obtained by vibrometry; blue and red lines: sound insulation curves obtained by means of ISO 10140-2. (b) Spectrum in 1/48th octave bands of the sound reduction index determined by applying a Rayleigh calculation on vibrometry data (green: Wall 1; black: Wall 2); combined spectrum (combi) of the two walls in 1/3rd octave band (blue dashed: Wall 1; red dashed: Wall 2).

Table 2. Airborne sound insulation values of Wall 1 and Wall 2 and their differences, expressed in terms of single number ratings extracted from microphone-based data and from combined microphone-vibrometry data. Values in brackets give results with taking to account the recommended standard deviation $2 \mathrm{~dB}$ of method.

\begin{tabular}{|c|c|c|c|c|c|c|c|}
\hline Symbol & Wall $1_{\text {combi }}$ & Wall 2 combi & Wall 1 ISO & Wall 2 ISO & $\Delta R_{w, \text { combi }}$ & $\Delta R_{w, \text { ISO }}$ & $\Delta R_{w, \text { Weber }}[13]$ \\
\hline$C(\mathrm{~dB})$ & -2 & -5 & -2 & -3 & -3 & -1 & $5(3)$ \\
\hline$C_{t r}(\mathrm{~dB})$ & -7 & -10 & -6 & -9 & -3 & -3 & $2(0)$ \\
\hline$C_{50-3150}(\mathrm{~dB})$ & -3 & -6 & -3 & -4 & -3 & -1 & - \\
\hline$C_{50-5000}(\mathrm{~dB})$ & -2 & -5 & -2 & -3 & -3 & -1 & - \\
\hline$C_{100-5000}(\mathrm{~dB})$ & -2 & -4 & -1 & -3 & -2 & -2 & - \\
\hline$C_{t r, 50-3150}(\mathrm{~dB})$ & -11 & -14 & -10 & -12 & -3 & -2 & - \\
\hline$C_{t r, 100-5000}(\mathrm{~dB})$ & -7 & -10 & -6 & -9 & -3 & -3 & - \\
\hline
\end{tabular}




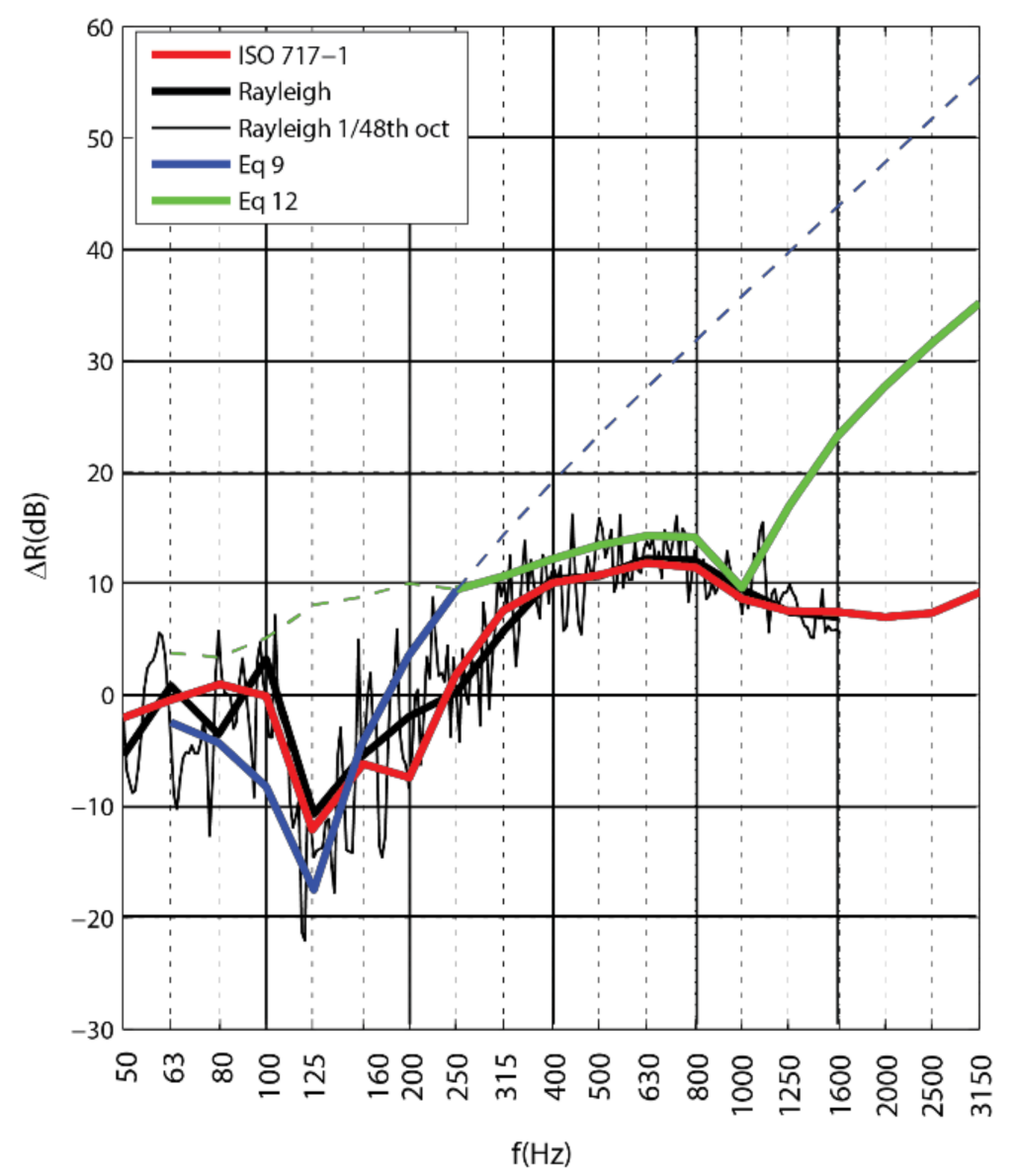

Figure 8. The sound reduction improvement index $\Delta R=R_{\text {wall } 2}-R_{\text {wall } 1}$ based on microphone measurement results and vibrometry technique.

Figure 8 also shows a prediction of the $\Delta R$-spectrum based on Equation (8), which was proposed by Weber et al. The corresponding $\Delta R_{\mathrm{W}}$ value overestimates the measured value by about 7-9 $\mathrm{dB}$ (Table 2), due to the $\Delta R_{\mathrm{W}}$ spectrum overestimating the experimental data, especially above the coincidence frequency. The values in parentheses denote the average standard deviation $(2 \mathrm{~dB})$ of results presented by ISO standard [42].

However, the Cremer expression in Equation (13) [59] fits quite well for spectrum above the resonance of the ETICS system and up to the coincidence frequency of ETICS plaster finishing layer (theoretical coincidence frequency of $25 \mathrm{~mm}$ lime plaster layer: $f_{c}=1080 \mathrm{~Hz}$ ):

$$
\Delta R_{f_{0}<f<f_{c}}=20 \log \left(m \cdot \frac{f}{\left(\frac{\rho_{0} \cdot c}{\pi}\right)}\right)+10 \log \left(\frac{f}{f_{c}}-1\right)+10 \log (\eta)-2
$$

with $\eta$ the structural loss factor of the wall and $\rho_{0}$ the density of air.

\section{Conclusions}

This paper verifies the impact of the use of an external thermal composite system (ETICS) on the airborne sound insulation. For optimum accuracy over a wide frequency range, standardized microphone-based sound transmission measurements are combined with accelerometer-based vibrometry measurements. Consistency was found between: (1) structural resonance frequencies and bending wave velocity dispersion curves determined by vibrometry; (2) spectral features of the 
sound reduction index; (3) ETICS mass-spring-mass resonance induced dip in the acoustic insulation spectrum; and (4) coincidence induced dip.

The influence of the implementation of ETICS on the sound transmission properties of the supporting wall is analyzed in detail on a grid $15 \mathrm{~cm} \times 15 \mathrm{~cm}$. Results obtained by accelerometer based on vibrometry measurements, with optimum accuracy at low frequencies, are combined with measurements based on ISO-10140 standard method, e.g., by means of microphones, with best accuracy for frequencies above $1500 \mathrm{~Hz}$.

The measurements confirm that, due to the induced mass-spring-mass resonance, application of ETICS decreases the sound insulation properties in the low frequency range $(<200 \mathrm{~Hz})$, while, due to the dual layer mass law, the sound insulation increases with frequency from $+6 \mathrm{~dB} /$ octave to $+12 \mathrm{~dB} /$ octave for high frequencies. The dip in the low frequency part of the insulation curve is quite cumbersome, given that ETICS facades are often exposed to broad band traffic noise with strong low frequency components. The reduction of sound insulation described by the single number quantity is about 1-2 dB, which might give impression of an insignificant difference. However, the detailed analysis of sound transmission spectra of measured walls shows deep dips in narrow frequency bands. When such leaking frequencies coincide with strong spectral components in the noise, then this can result in strong acoustic discomfort. From hearing research, it is well known that, although low frequencies are less audible than middle and high ones in the case of low or moderate sound levels, the dynamics of human ear becomes smaller towards deeper tones [39]. This means that small increases of barely audible low frequency sounds will be perceived as much larger increases.

The measurement results show significant differences with the predictions of the ETICS induced effect on $\Delta R$ and $\Delta R_{W}$ using a model by Weber et al. [12,13]. For the single number quantity prediction, the difference was $7(9) \mathrm{dB}$ (with the prediction model uncertainty ( $2 \mathrm{~dB})$ considered).

The engineering $\Delta R$ prediction model is recommended by combining the spectral model by Weber et al. for the lower frequencies and the model by Cremer et al. [59]. Weber's model corresponds with the measured spectra well in frequency range around and below ETICS resonance frequency. On the other hand, Cremer's equation corresponds to the part up to coincidence frequency of the ETICS mass part (the external plaster layer). That means, for frequencies above the resonance of the ETICS system and up to the coincidence frequency of ETICS plaster finishing layer, a better agreement with the measurement data in terms of $\Delta R$ is obtained. It should be underlined that, to make firm conclusions about the validity of the presented approach of combining different spectral models, comparisons with experimental data on more samples will be needed.

Acknowledgments: This work was supported by the European Commission, H2020-MSCA-RISE-2015 project 690970, "PAPABUILD" APVV-16-0126 and VEGA 1/0067/16.

Author Contributions: Daniel Urbán, N.B. Roozen, Herbert Muellner, Peter Zat'ko, Monika Rychtáriková and Christ Glorieux conceived and designed the experiments; Herbert Muellner and Alexander Niemczanowski performed the experiments; Daniel Urbán and N.B. Roozen analyzed the data; Daniel Urbán and N.B. Roozen contributed construction analysis tools; and Daniel Urbán wrote the paper.

Conflicts of Interest: The authors declare no conflict of interest.

\section{References}

1. Gong, X.; Akashi, Y.; Sumiyoshi, D. Optimization of passive design measures for residential buildings in different Chinese areas. Build. Environ. 2012, 58, 46-57. [CrossRef]

2. D'Orazio, M.; Cursio, G.; Graziani, L.; Aquilanti, L.; Osimani, A.; Clementi, F.; Yéprémian, C.; Lariccia, L.; Amoroso, S. Effects of water absorption and surface roughness on the bioreceptivity of ETICS compared to clay bricks. Build. Environ. 2014, 77, 20-28. [CrossRef]

3. Barreira, E.; de Freitas, V.P. Experimental study of the hygrothermal behaviour of External Thermal Insulation Composite Systems (ETICS). Build. Environ. 2013, 63, 31-39. [CrossRef]

4. Johansson, W.L.; Sandin, K. Estimation of mould growth levels on rendered façades based on surface relative humidity and surface temperature measurements. Build. Environ. 2010, 45, 1153-1160. [CrossRef] 
5. Al-Homoud, M.S. Performance characteristics and practical applications of common building thermal insulation materials. Build. Environ. 2005, 40, 353-366. [CrossRef]

6. Thermal Protection of Buildings. Thermal Performance of Buildings and Components. Part 2: Functional Requirements; STN 73 0540-2/Z1; STN: Bratislava, Slovak, 2016.

7. ISO. ISO 52003-1 Energy Performance of Buildings-Indicators, Requirements, Ratings and Certificates-Part 1: General Aspects and Application to the Overall Energy Performance; ISO: Geneva, Switzerland, 2017.

8. Pietruschka, D.; Varga, E.; Drechsler, A.; Marin, R.; Eicker, U.; Fischer, H. Energetische und Akustische Sanierung von Wohngebäuden-vom Altbau zum Akustisch Optimierten Passivhaus; Forschungsbericht; Hochschule für Technik: Stuttgart, Germany, 2012.

9. Nurzynski, J. The effect of additional thermal lining on the acoustic performance of a wall. In Proceedings of the Forum Acusticum 2008, Paris, France, 29 June-4 July 2008.

10. Guigou-Carter, C.; Foret, R.; Villot, M.; Chene, J.B. Effect of thermal renovation on acoustic performance of buildings. In Proceedings of the Euronoise 2009, Edinburgh, UK, 26-28 October 2009.

11. Magarini, A.; Scamoni, F.; Scrosati, C. Integrated acoustic and thermo-hygrometric performances of building walls, for more efficient refurbishment strategies: First evaluations. In Proceedings of the 21st International Congress on Sound and Vibration 2014, Beijing, China, 13-17 July 2014.

12. Weber, L.; Kaltbeityel, B. Schalldämmung von Wärmedämm-Verbundsystemen mit Zweilagiger Dämmschicht; Fraunhofer IRB Verlag: Stuttgart, Germany, 2016.

13. Weber, L.; Müller, S. Schallschutz bei Wärmedämm-Verbundsystemen; Fraunhofer IRB Verlag: Stuttgart, Germany, 2015.

14. Weber, L.; Zhang, Y.; Brandstetter, D. Influence of Wall Construction on the Acoustical Behaviour of ETHICS. In Proceedings of the DAGA 2002, Bochum, Germany, 4-8 March 2002.

15. Weber, L.; Buchele, A. Acoustic Refurbishment of Residential Buildings with Additional Linings and Additional Lining Constructions-Calculation, Design, and Optimization; Abridged Version of Research Report B-BA 2/2008; Fraunhofer Institute for Building Physics (IBP): Stuttgart, Germany.

16. Weber, L. Effect of ETHICS on the flanking transmission of outer walls. In Proceedings of the Fortschritte der Akustik-DAGA, Strasbourg, France, 22-25 March 2004.

17. Weber, L.; Brandstetter, D. Einheitliche Schalltechnische Bemessung von Wärmedämm-Verbundsystemen, -Ergänzung des Berechnungsverfahrens; IBP-Bericht B-BA 4/2005; Fraunhofer IRB Verlag: Stuttgart, Germany, 2002.

18. Weber, L. Einheitliche Schalltechnische Bemessung von Wärmedämm-Verbundsystemen-Ergänzung des Berechnungsverfahrens; Fraunhofer IRB Verlag: Stuttgart, Germany, 2005.

19. Scholl, W. Schalldämmung mit Wärmedämmverbundsystemen. Bauphysik 1999, 21, 20-28.

20. ISO. ISO 717-1:2013. Acoustics-Rating of Sound Insulation in Buildings and of Building Elements-Part 1: Airborne Sound Insulation; ISO: Geneva, Switzerland, 2013.

21. European Commission. Report from the Commission to the European Parliament and the Council on the Implementation of the Environmental Noise Directive in Accordance with Article 11 of Directive 2002/49/EC; European Commission: Belgium, 2017.

22. Miedema, H.M.; Oudshoorn, C.G. Annoyance from transportation noise: Relationships with exposure metrics DNL and DENL and their confidence intervals. Environ. Health Perspect. 2001, 109, 409. [CrossRef] [PubMed]

23. Muzet, A. Environmental noise, sleep and health. Sleep Med. Rev. 2007, 11, 135-142. [CrossRef] [PubMed]

24. Lercher, P.; Evans, G.W.; Meis, M. Ambient noise and cognitive processes among primary schoolchildren. Environ. Behav. 2003, 35, 725-735. [CrossRef]

25. Babisch, W.; Swart, W.; Houthuijs, D.; Selander, J.; Bluhm, G.; Pershagen, G.; Sourtzi, P. Exposure modifiers of the relationships of transportation noise with high blood pressure and noise annoyance. J. Acoust. Soc. Am. 2012, 132, 3788-3808. [CrossRef] [PubMed]

26. ISO. ISO 10140-2:2010. Acoustics-Laboratory Measurement of Sound Insulation of Building Elements Part 2: Measurement of Airborne Sound Insulation; ISO: Geneva, Switzerland, 2010.

27. ISO. ISO 10140-5:2010. Acoustics-Laboratory Measurement of Sound Insulation of Building Elements Part 5: Requirements for Test Facilities and Equipment; ISO: Geneva, Switzerland, 2010. 
28. Zat'ko, P.; Urbán, D.; Tomašovič, P.; Rychtáriková, M. Acoustic Performance of the External Thermal Composite Insulation Systems Influence in Slovakia. In Proceedings of the Fortschritte der Akustik-DAGA 2016, Aachen, Germany, 14-17 March 2016.

29. Foret, R.; Guigou-Carter, C.; Villot, M. Effect of thermal insulation systems on acoustic performances of ancient building construction elements. In Proceedings of the Internoise and Noise-on Institute of Noise Control Engineering, Portugal, 13-16 June 2010.

30. Miskinis, K.; Dikavicius, V.; Buska, A. Acoustic and thermal properties of building envelope with ETICS. In Proceedings of the 23rd International Congress on Sound and Vibration, Athens, Greece, 10-14 July 2016.

31. Guigou-Carter, C.; Foret, R.; Wetta, R.; Ducruet, P.; Villot, M. Comparison of measured and predicted sound insulation for a thermal retrofitted building. Noise Control Eng. J. 2011, 59, 278-289. [CrossRef]

32. Santoni, A.; Bonfiglio, P.; Davy, J.L.; Fausti, P.; Pompoli, F.; Pagnoncelli, L. Sound transmission loss of ETICS cladding systems considering the structure-borne transmission via the mechanical fixings: Numerical prediction model and experimental evaluation. Appl. Acoust. 2017, 122, 88-97. [CrossRef]

33. Allard, J.; Atalla, N. Propagation of Sound in Porous Media: Modelling Sound Absorbing Materials; John Wiley \& Sons: Hoboken, NJ, USA, 2009.

34. Fausti, P.; García, T.C.; Ingelaere, B.; Machimbarrena, M.; Monteiro, C.; Santoni, A.; Smith, S. Building Acoustics throughout Europe Volume 1: Towards a Common Framework in Building Acoustics Throughout Europe; COST Office and Authors, COST Action TU0901, COST Office: Brussels, Belgium, 2014.

35. Wittstock, V. On the uncertainty of single-number quantities for rating airborne sound insulation. Acta Acust. United Acust. 2007, 93, 375-386.

36. Buratti, C.; Belloni, E.; Moretti, E. Façade noise abatement prediction: New spectrum adaptation terms measured in field in different road and railway traffic conditions. Appl. Acoust. 2014, 76, 238-248. [CrossRef]

37. Rasmussen, B.; Rindel, J.H. Concepts for evaluation of sound insulation of dwellings-from chaos to consensus. In Proceedings of the Forum Acusticum, Budapest, Hungary, 29 August-2 September 2005.

38. Rasmussen, B. Sound insulation between dwellings-Requirements in building regulations in Europe. Appl. Acoust. 2010, 71, 373-385. [CrossRef]

39. Rychtáriková, M.; Muellner, H.; Chmelík, V.; Roozen, N.B.; Urbán, D.; Garcia, D.P.; Glorieux, C. Perceived Loudness of Neighbour Sounds Heard Through Heavy and Light-Weight Walls with Equal $\mathrm{R}_{\mathrm{w}}+\mathrm{C}$ 50-5000. Acta Acust. United Acust. 2016, 102, 58-66. [CrossRef]

40. Weber, L. Akustisches Berechnungsmodell für Wärmedämm-Verbundsysteme. In Proceedings of the DAGA 2005, Munich, Germany, 14-17 March 2005.

41. Zat'ko, P. Kontaktné zatepl'ovacie systémy a ich vplyv na akustické vlastnosti stavebných konštrukcií. Fyzikálne Faktory Prostredia 2014, 4, 21-24.

42. ISO. ISO 12354-1. Building Acoustics-Estimation of Acoustic Performance of Buildings from the Performance of Elements-Part 1: Airborne Sound Insulation between Rooms; ISO: Geneva, Switzerland, 2017.

43. De Salis, M.F.; Oldham, D.J.; Sharples, S. Noise control strategies for naturally ventilated buildings. Build. Environ. 2002, 37, 471-484. [CrossRef]

44. Roozen, N.B.; Labelle, L.; Rychtáriková, M.; Glorieux, C. Determining radiated sound power of building structures by means of Laser Doppler vibrometry. J. Sound Vib. 2015, 346, 81-99. [CrossRef]

45. Squicciarini, G.; Thompson, D.J.; Corradi, R. The effect of different combinations of boundary conditions on the average radiation efficiency of rectangular plates. J. Sound Vib. 2014, 333, 3931-3948. [CrossRef]

46. Roozen, N.B.; Muellner, H.; Labelle, L.; Rychtáriková, M.; Glorieux, C. Influence of panel fastening on the acoustic performance of light-weight building elements: Study by sound transmission and laser scanning vibrometry. J. Sound Vib. 2015, 346, 100-116. [CrossRef]

47. Villot, M.; Guigou, C.; Gagliardini, L. Predicting the acoustical radiation of finite size multi-layered structures by applying spatial windowing on infinite structures. J. Sound Vib. 2001, 245, 433-455. [CrossRef]

48. Cheng, Z.; Fan, J.; Wang, B.; Tang, W. Radiation efficiency of submerged rectangular plates. Appl. Acoust. 2012, 73, 150-157. [CrossRef]

49. Koopmann, G.H.; Benner, H. Method for Computing the Sound Power of Machines Based on the Helmholtz Integral. J. Acoust. Soc. Am. 1982, 71, 78-89. [CrossRef]

50. Fahy, F. Sound and Structural Vibration: Radiation, Transmission and Response; Academic Press: London, UK, 1985. 
51. Lamancusa, J.S. Numerical optimization techniques for structuralacoustic design of rectangular panels. Comput. Struct. 1993, 48, 661-675. [CrossRef]

52. Waterhouse, R.V. Interference patterns in reverberant sound fields. J. Acoust. Soc. Am. 1955, 27, $247-258$. [CrossRef]

53. Vorländer, M. Revised relation between the sound power and the average sound pressure level in rooms and consequences for acoustic measurements. Acta Acust. United Acust. 1995, 81, 332-343.

54. ISO. ISO 3741. Acoustics-Determination of Sound Power Levels and Sound Energy Levels of Noise Sources Using Sound Pressure-Precision Methods for Reverberation Test Rooms; ISO: Geneva, Switzerland, 2010.

55. Vernier. EN 29052-1. Acoustics. Determination of Dynamic Stiffness. Part 1: Materials Used under Floating Floors in Dwellings; Vernier: Geneva, Switzerland, 1992.

56. Roozen, N.B.; Labelle, L.; Leclere, Q.; Ege, K.; Alvarado, S. Non-contact experimental assessment of apparent dynamic stiffness of constrained-layer damping sandwich plates in a broad frequency range using a $\mathrm{Nd}$ : YAG pump laser and a laser Doppler vibrometer. J. Sound Vib. 2017, 395, 90-101. [CrossRef]

57. Williams, E.G. Fourier Acoustics, Sound Radiation and Nearfield Acoustical Holography; Academic Press: London, UK, 1999.

58. Xie, G.; Thompson, D.J.; Jones, C.J.C. The radiation efficiency of baffled platesand strips. J. Sound Vib. 2005, 280, 181-209. [CrossRef]

59. Cremer, L. Theorie der Schalldämmung dünner Wände bei schrägem Einfall. Akust. Z. 1942, 7, 81-104.

(C) 2018 by the authors. Licensee MDPI, Basel, Switzerland. This article is an open access article distributed under the terms and conditions of the Creative Commons Attribution (CC BY) license (http://creativecommons.org/licenses/by/4.0/). 